Journal of Mechanical Engineering and Sciences (JMES)

ISSN (Print): 2289-4659; e-ISSN: 2231-8380; Volume 3, pp. 271-280, December 2012

(C) Universiti Malaysia Pahang, Pekan, Pahang, Malaysia

DOI: http://dx.doi.org/10.15282/jmes.3.2012.3.0025

\title{
A NUMERICAL STUDY OF FORCED CONVECTION HEAT TRANSFER OVER A SERIES OF FLAT TUBES BETWEEN PARALLEL PLATES
}

\author{
Tahseen A. Tahseen ${ }^{1}$, M. Ishak ${ }^{1,2}$ and M.M. Rahman ${ }^{1,2}$ \\ ${ }^{1}$ Faculty of Mechanical Engineering, University Malaysia Pahang \\ 26600 Pekan, Pahang, Malaysia \\ Phone: +609-424-6239; Fax: +609-424-6222 \\ Email: mahadzir@ump.edu.my \\ ${ }^{2}$ Automotive Engineering Centre, Universiti Malaysia Pahang, \\ 26600 Pekan, Pahang, Malaysia \\ Email: mustafizur@ump.edu.my
}

\begin{abstract}
This paper presents the numerical study on two-dimensional forced convection heat transfer across three in-line flat tubes confined in a channel under incompressible, steady-state conditions. This system is solved in body-fitted coordinates (BFC) using the finite volume method (FVM). The constant heat flux is imposed on the surface of the tubes as the thermal boundary conditions. The range of the longitudinal pitch-todiameter ratio $\left(\mathrm{S}_{\mathrm{L}} / \mathrm{D}_{\mathrm{s}}\right)$ of $2.0-4.0$ is considered, the Reynolds number varies within the range 25-300, and the Prandtl number is taken as 0.7. The temperature contours, local Nusselt number distributions at the tube surface and mean Nusselt number were analyzed. The strength of the heat transfer between the surface of the tubes and the air flow increases with an increase in Reynolds number and pitch-to-diameter ratio.
\end{abstract}

Keywords: Cross-flow; finite volume; forced convection; in-line flat tube; body-fitted coordinates.

\section{INTRODUCTION}

Compact heat exchangers are used in a wide diversity of applications. Classic among them are the heat exchangers used in air conditioning, automobiles, electronics cooling, aircraft and spacecraft, solar, geothermal systems, and ocean thermal energy conservation. As well as those resulting from the need for lightweight, space-saving, heat exchangers in the economic development of compact surfaces (Kupprn, 2000). Flat tubes, however, have not been investigated to the same extent, regardless of the fact that they play an important role in many technical applications, such as in new heat exchangers and automotive radiators. It has recently been a flat tube design view for use in automotive, air conditioning evaporators and condensers (Webb, 1993). Flat tube heat exchangers are estimated have the lowest pressure drop on the air side and to improve heat transfer coefficients compared to an air side with circular tube heat exchangers. The low pressure is expected to be less than that of a circular pipe, because there is a smaller wake area. For the same reason it is expected that the vibration and noise will be reduced in flat tube heat exchangers compared to circular tube heat exchangers. The importance of heat transfer and fluid flow appearance over tube banks in the design of heat exchangers is well known. Comprehensive experimental (Zukauskas, 1972), numerical (Jayavel \& Tiwari, 2009; Marchi \& Hobmeir, 2007; Rahmani, Mirzaee, \& Shirvani, 2005; Wang, Penner, \& Ormiston, 2000; Wilson \& Bassiouny, 2000), and 
experimental and numerical studies (Matos, Vargas, Laursen, \& Bejan, 2004; Sumner, 2010; Rosdzimin, Zuhairi, \& Azwadi, 2010) on circular tube banks have been previously conducted. Based on previous studies published in the literature, one can infer from this that the form of a tube and its arrangement has a significant effect on heat transfer (Fowler \& Bejan, 1994; Mandhani, Chhabra, \& Eswaran, 2002; Vijaya Lakshmi, Subrahmanyam, Dharma Rao, \& Sharma, 2011; Suryanarayana, Srinivasa Rao, Reddy Prasad, Sharma, \& Sarma,, 2011).

Literature on flow over a series of flat tubes and many other shapes is limited, the exception being a recent study on performance data presented for a range of flat tube and louvered plate fin surfaces (Achaichia \& Cowell, 1988), in which the range of Reynolds numbers was $120 \leq \mathrm{Re} \leq 8000$. The results showed duct flow too far up the velocity range, especially if the louver pitch is small along with a large fin pitch and/ or a small louver angle. Has developed links provided here measurements on samples on the scale that represent those used in the industry, and as such they are widely applicable. Bahaidarah, Ijaz, and Anand (2006) presented results for numerical steady, laminar, two-dimensional, incompressible flows over a series of circular, flat, oval, and diamond shapes. The result shows that flat and oval tubes offer greater flow resistance and heat transfer rates compared to circular tubes for all Reynolds numbers. Beale and Spalding (1999) carried out a numerical investigation on transient incompressible flows in inline square and rotated square tube banks within the range of Reynolds numbers 30 $\leq \operatorname{Re} \leq 3000$, and with a ratio of the pitch to diameter equal to 2:1. They calculated the drag, lift, pressure drop, and heat transfer. Numerical simulations of two-dimensional, incompressible, unsteady flows over a bank of flat tubes for both in-line and staggered configurations for isothermal and isoflux boundary conditions. The result correlations are planned for both pressure drops, and the Nusselt number and the optimal configurations have been identified (Benarji, Balaji, \& Venkateshan, 2008). Chen, Fiebig, and Mitra (1998a, 1998b) presented the results for three-dimensional laminar, incompressible, and steady flows and heat transfer over finned oval tubes. The range of Reynolds numbers was $100 \leq R e \leq 500$, and the fin parameter $F_{i}$. This paper presents the heat transfer and fluid flow over three flat tubes arranged in-line between two parallel plates for various Reynolds numbers with different longitudinal pitch to tube small diameter ratios.

\section{MATHEMATICAL FORMULATION}

The basic configuration of two-dimensional, laminar, steady, constant and incompressible flow is shown in Figure 1. The dimensionless continuity equations of momentum and energy in Cartesian coordinates are expressed in Eqs. (1)-(2) respectively (Bejan, 2004):

$$
\begin{gathered}
\frac{\partial U}{\partial X}+\frac{\partial V}{\partial Y}=0 \\
\frac{\partial(U \phi)}{\partial X}+\frac{\partial(V \phi)}{\partial Y}=\frac{\partial}{\partial X}\left(\frac{1}{\Gamma} \frac{\partial \phi}{\partial X}\right)+\frac{\partial}{\partial Y}\left(\frac{1}{\Gamma} \frac{\partial \phi}{\partial Y}\right)+S_{\phi}=0
\end{gathered}
$$


where, $\phi=\left[\begin{array}{c}U \\ V \\ \theta\end{array}\right], \Gamma=\left[\begin{array}{c}\operatorname{Re} \\ \operatorname{Re} \\ \operatorname{Re} \operatorname{Pr}\end{array}\right], S_{\phi}=\left[\begin{array}{c}-\frac{\partial P}{\partial X} \\ -\frac{\partial P}{\partial X} \\ 0\end{array}\right]$

The governing equation dimensionless formed into dimensionless forms upon the incorporation of the following non-dimensional variables.

$$
\begin{aligned}
& (X, Y)=\frac{(x, y)}{H}, P=\frac{p}{\rho U_{\infty}^{2}},(U, V)=\frac{(u, v)}{U_{\infty}} \\
& \theta=\frac{T-T_{\infty}}{T_{w}-T_{\infty}}, \operatorname{Re}_{D}=\frac{U_{\infty} H}{v}, \operatorname{Pr}=\frac{\mu C_{p}}{k}
\end{aligned}
$$

The uniform inlet velocity, fully developed outflow, and a combination of symmetrical and no-slip tube surfaces on the bottom and top boundaries are considered as the boundary conditions. The boundary conditions prescribed for $U, V$ and $\theta$ are also shown in Figure 1.

Inlet flow of the domain: $U=1.0, V=0, \theta=0$

Outflow of the domain: $\frac{\partial U}{\partial X}=\frac{\partial V}{\partial X}=\frac{\partial \theta}{\partial X}=0$

Plate surface: $U=V=0, \frac{\partial \theta}{\partial \mathrm{Y}}=0$

Tube surface: $U=V=0, \theta=0$

Symmetry: $\frac{\partial U}{\partial Y}=\frac{\partial \theta}{\partial Y}=V=0$

The heat transfer coefficient $\left(h_{x}\right)$ can be expressed in dimensionless form by the local and average Nusselt numbers $\mathrm{Nu}$ and $\overline{\mathrm{Nu}}$, which are defined in Eqs. (5) and (6), respectively.

$$
\begin{aligned}
N u_{x}=\frac{h_{x} H}{k} & =\frac{-\left(\frac{\partial T}{\partial y}\right) H}{T_{w}-T_{\infty}}=-H \frac{\partial T}{\partial y} \\
\overline{N u} & ==\frac{1}{d A} \int N u_{x} d A
\end{aligned}
$$

The continuity equation has no diffusion or source terms. It will be used to derive an equation for pressure correction. The grid generation scheme based on elliptic partial differential equations is used to generate the curvilinear coordinates. Eq. (2) can be transformed from the physical domain to the computational domain according to the following transformation $\varsigma=\varsigma(x, y), \eta=\eta(x, y)$ (Thompson, Warsi, \& Martin, 1997). The final form of the transformed equation can be written as in Eq. (7): 


$$
\frac{\partial}{\partial \varsigma}\left(\phi G_{1}\right)+\frac{\partial}{\partial \eta}\left(\phi G_{2}\right)=\frac{\partial}{\partial \varsigma}\left(\frac{\Gamma}{J}\left(\alpha \frac{\partial \phi}{\partial \varsigma}-\gamma \frac{\partial \phi}{\partial \eta}\right)\right)+\frac{\partial}{\partial \eta}\left(\frac{\Gamma}{J}\left(\beta \frac{\partial \phi}{\partial \eta}-\gamma \frac{\partial \phi}{\partial \varsigma}\right)\right)+J S_{\phi}
$$

where $G_{1}$ and $G_{2}$ are the contravariant velocity components, $J$ is the Jacobian of the transformation in the computational plane, and $\alpha, \beta$, and $\gamma$ are the coefficients of transformation.

$$
\begin{aligned}
& G_{1}=U \frac{\partial Y}{\partial \eta}-V \frac{\partial X}{\partial \eta} ; G_{2}=V \frac{\partial X}{\partial \varsigma}-U \frac{\partial Y}{\partial \varsigma} ; \mathrm{J}=\left(\frac{\partial \mathrm{X}}{\partial \varsigma} \frac{\partial \mathrm{Y}}{\partial \eta}-\frac{\partial \mathrm{Y}}{\partial \varsigma} \frac{\partial X}{\partial \eta}\right) \\
& \alpha=\left(\frac{\partial x}{\partial \eta}\right)^{2}+\left(\frac{\partial y}{\partial \eta}\right)^{2} ; \gamma=\left(\frac{\partial x}{\partial \varsigma} \frac{\partial x}{\partial \eta}\right)+\left(\frac{\partial y}{\partial \varsigma} \frac{\partial y}{\partial \eta}\right) ; \beta=\left(\frac{\partial x}{\partial \varsigma}\right)^{2}+\left(\frac{\partial y}{\partial \varsigma}\right)^{2}
\end{aligned}
$$

Equation (8) is solved numerically using a control volume-based finite volume method. The solution by the marching type procedure involves a series of twodimensional elliptic problems in the cross-stream plane, with a marching step size of $1 \times 10^{-4}$ along the axial distance. At each marching step the strong coupling of pressure and velocity in the cross-section was calculated by the SIMPLE-algorithm on a collocated non-orthogonal grid. It is used to adjust the velocity field to satisfy the conservation of mass (Patankar, 1980). For the computational calculations, a computer code is prepared in FORTRAN-90. In the numerical calculations a $662 \times 22$ grid arrangement is found to be sufficient for grid-independent solutions.

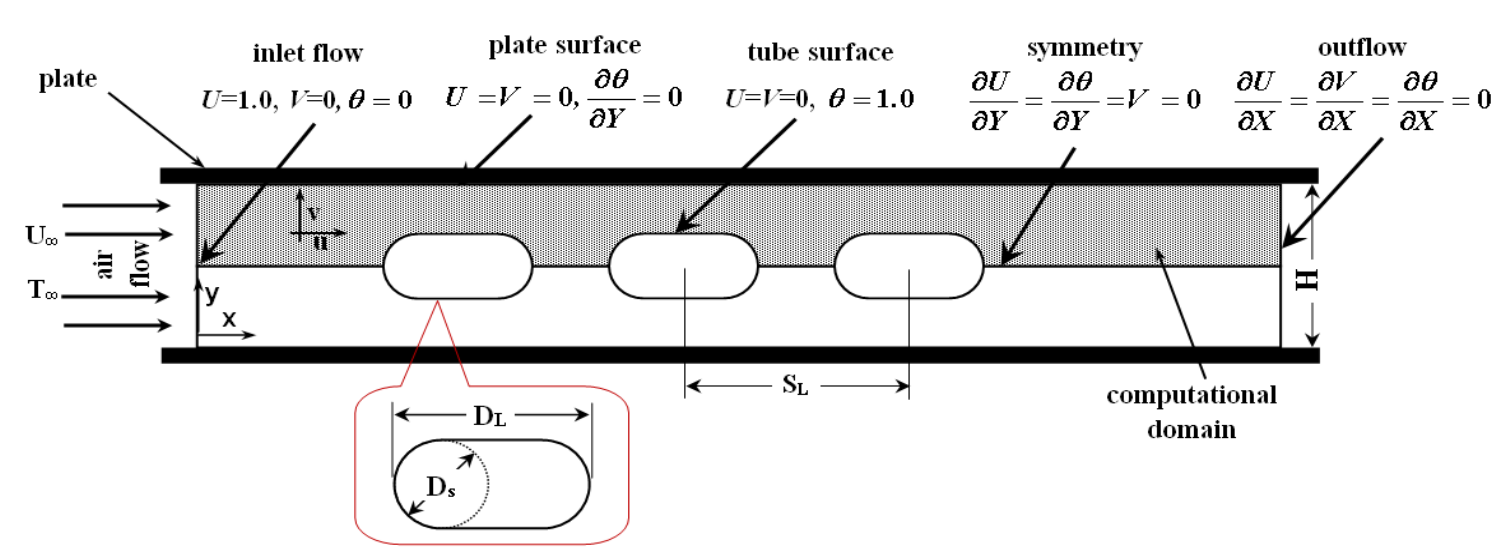

Figure 1. Flow domains studied with boundary conditions

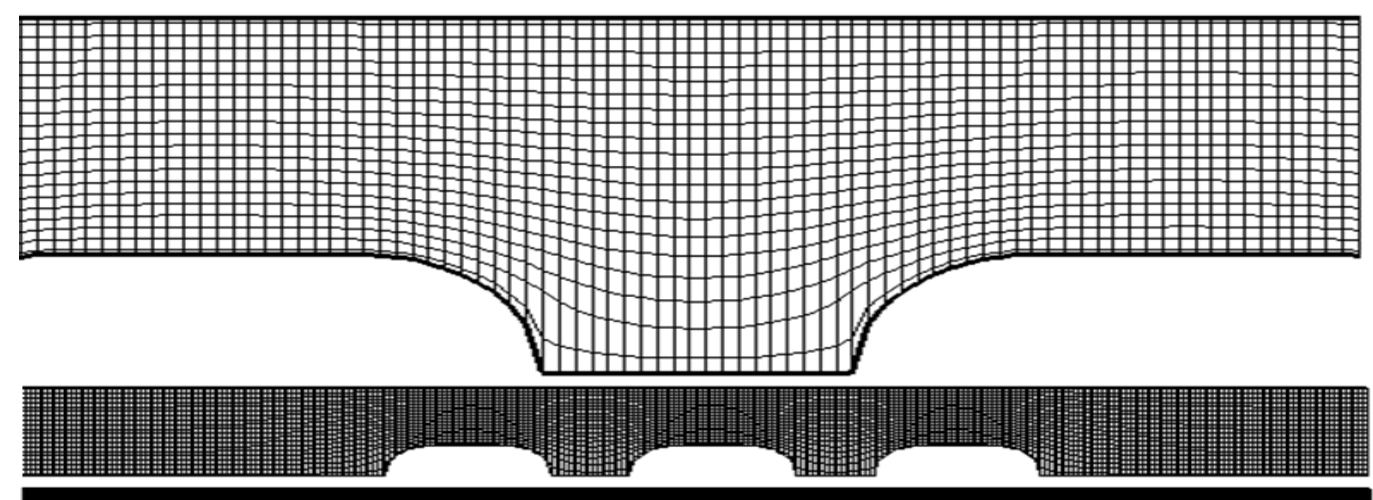

Figure 2. Schematic of grid systems generated by body-fitted coordinates (BFC). 


\section{VALIDATION}

The pressure drop of the third module of the series of circular tubes between two parallel plates was calculated using the code developed, and was compared with numerical estimates by Kundu (1989). Figure 3 shows a comparison between the present work with previous literature on pressure drops against Reynolds number at $\mathrm{Pr}=$ $0.7, \mathrm{~L} / \mathrm{D}=2$. 0 and $\mathrm{H} / \mathrm{D}=2$. 0 . It is clearly seen that a very good agreement is achieved between the present results and the numerical results of Kundu (1989).

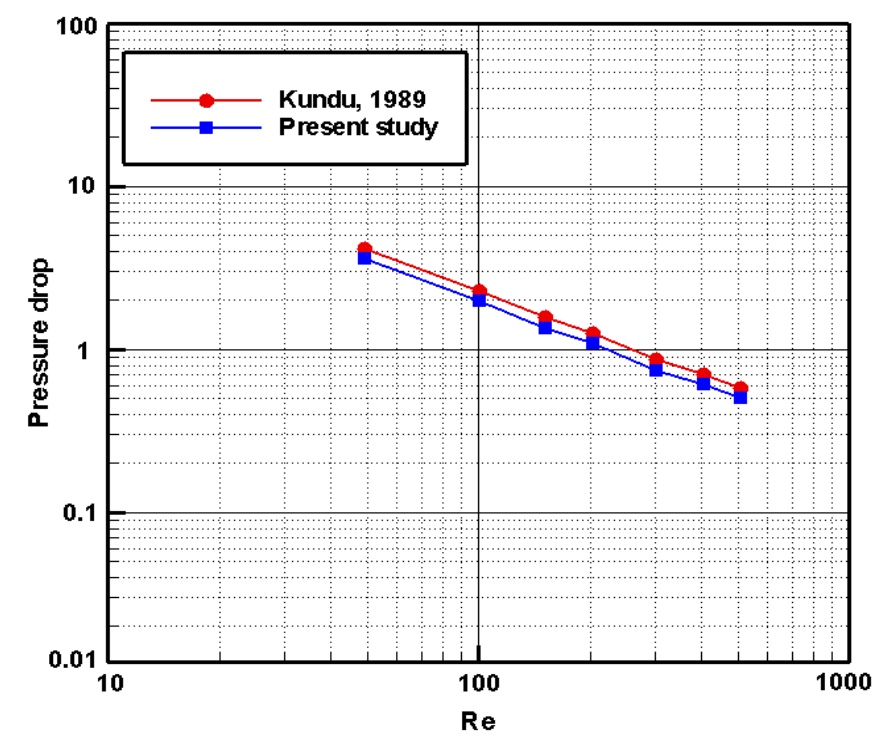

Figure 3. Validation with previous work (Kundu, 1989) in terms of pressure drop across third tube.

\section{RESULTS AND DISCUSSION}

The numerical solutions for laminar forced convection heat transfer across flow over three flat tubes placed in-line in a channel bounded by two parallel plates are presented. The range of tube pitch to the small diameter of the tube $\left(D_{s}\right)$ is 2.0 to 4.0 , and the Reynolds number ( $\mathrm{Re})$ varies within 25-300. For the temperature distribution isotherms floods, a lower air temperature at the inlet to higher air temperature as it reaches the hot tube surface. Figure 4 presents the effect of the Reynolds numbers on the isotherms for various $\mathrm{S}_{\mathrm{L}} / \mathrm{D}_{\mathrm{s}}$. It can be seen that the isotherm floods increase with Reynolds number, leading to a decrease due to the increase in cold air near the hot surface . It is clear that the hot layer thickness decreases with an increase in Reynolds number. It is also observed that the isotherm floods increase with a decrease in $S_{\mathrm{L}} / \mathrm{D}_{\mathrm{s}}$. Figure 5 presents the streamlines for various $S_{L} / D_{s}$ and Reynolds numbers. It is interesting to note the difference between the flows over the front of the tube when comparing the first tube with the last tube. A symmetric flow pattern can also be noted on the tubes considered in Figure 4. In this case there are very small flow recirculation regions behind of the first and second tubes. Clearly the same flow recirculation regions can be seen behind of the third and final tube with a low velocity of air at around $\mathrm{Re}=25$. An increase in the flow recirculation region behind the third tube occurs with an increase in Reynolds number, as well as a small effect in the flow recirculation region behind the first tube with an increase in Reynolds number. 


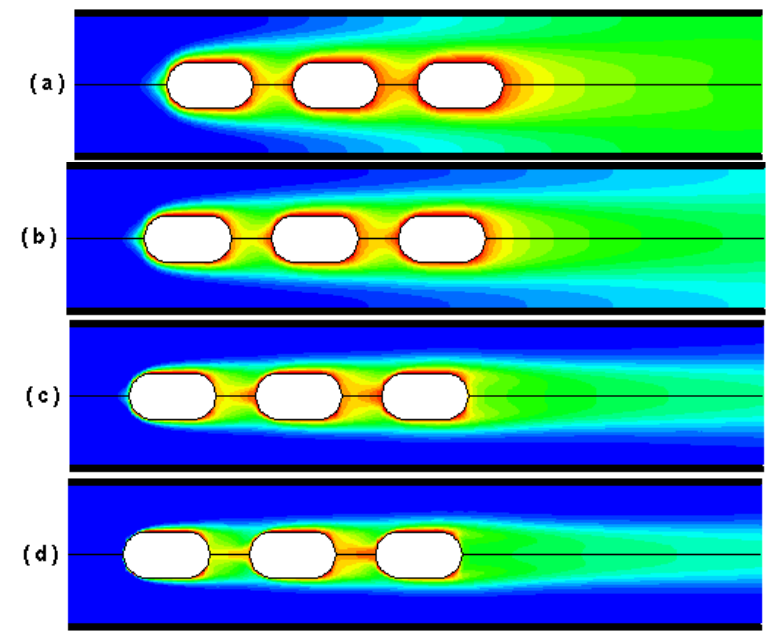

(a) $\mathrm{S}_{\mathrm{L}} / \mathrm{D}_{\mathrm{s}}=2.0$

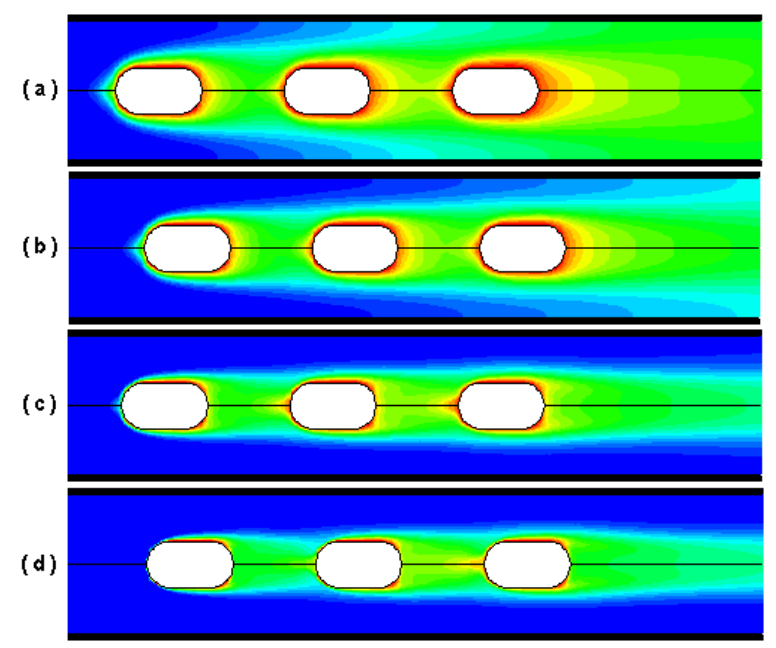

(b) $\mathrm{S}_{\mathrm{L}} / \mathrm{D}_{\mathrm{s}}=3.0$

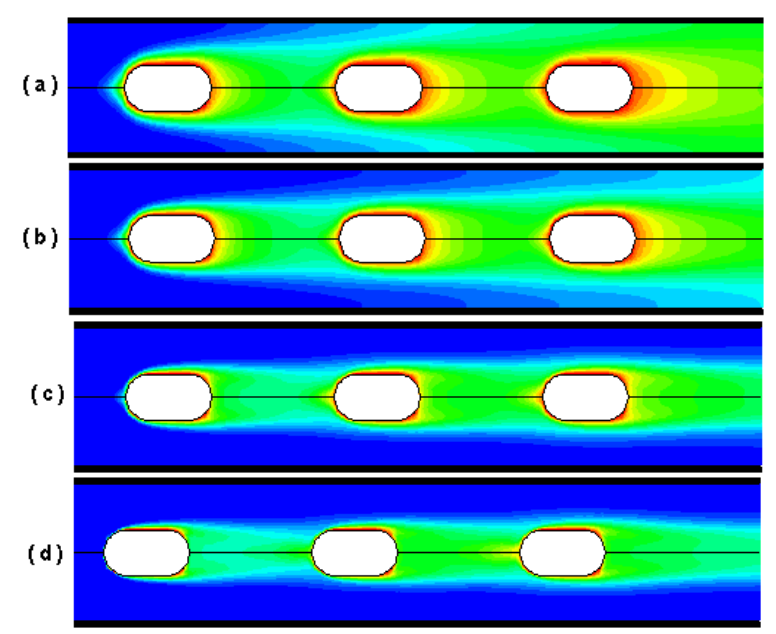

(c) $\mathrm{S}_{\mathrm{L}} / \mathrm{D}_{\mathrm{s}}=4.0$

Figure 4. Effect of Reynolds number on isotherms for (a) $\operatorname{Re}=25$, (b) $\operatorname{Re}=50$, (c) $\operatorname{Re}=150$ and (d) $\operatorname{Re}=300$. 
(a)

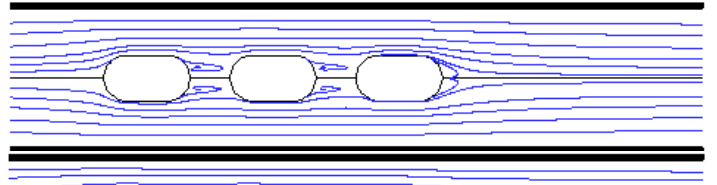

(b)

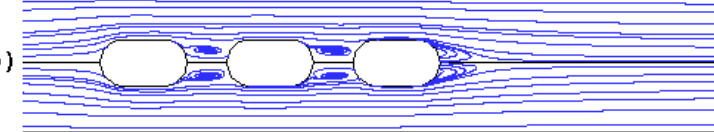

(c)

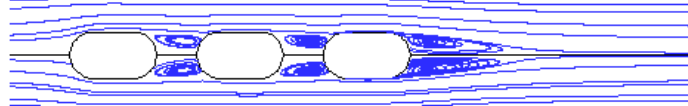

(d)

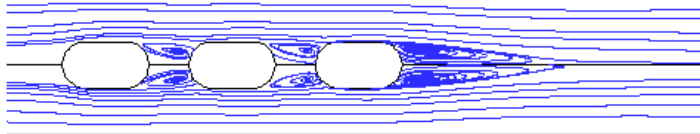

(a) $\mathrm{S}_{\mathrm{L}} / \mathrm{D}_{\mathrm{s}}=2.0$

(a)

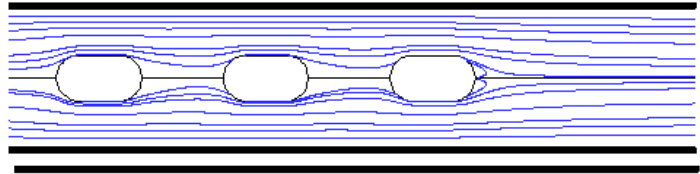

(b)
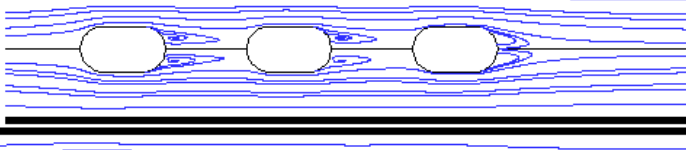

(c)

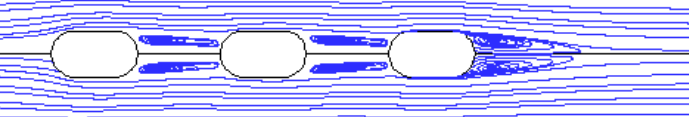

(d)

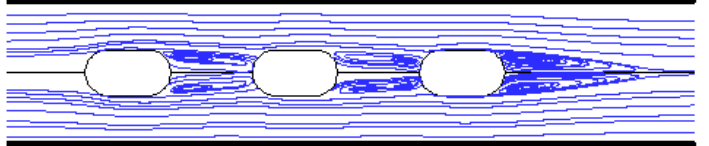

(b) $\mathrm{S}_{\mathrm{L}} / \mathrm{D}_{\mathrm{s}}=3.0$

(a)

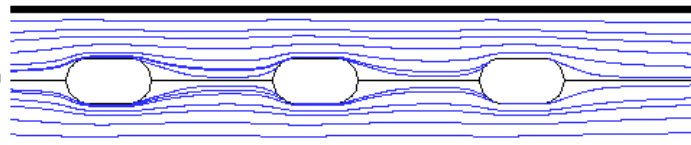

(b)
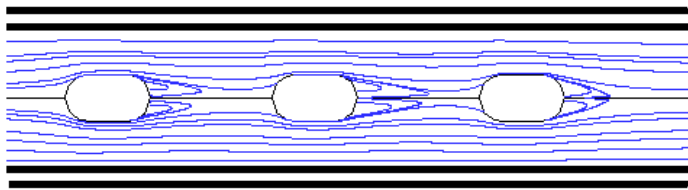

(c)

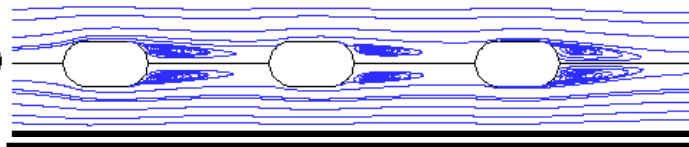

(d)

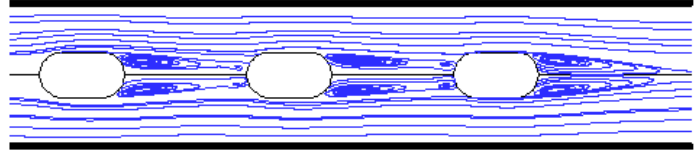

(c) $\mathrm{S}_{\mathrm{L}} / \mathrm{D}_{\mathrm{s}}=4.0$

Figure 5. Effect of Reynolds number on streamline for (a) $\operatorname{Re}=25$, (b) $\operatorname{Re}=50$, (c) $\operatorname{Re}$ $=150$ and $(\mathrm{d}) \operatorname{Re}=300$. 
Figure 6 shows the variation in average Nusselt number with Reynolds number for the three tubes for various $S_{L} / D_{s}$. It can be seen that the average Nusselt number increases with an increase in Re number. Clearly the greatest values of Nusselt number are found for the first tube. Thus the difference in temperature a large and the heat transfer coefficient is the maximum value, because it depends on the difference in temperature between the tube surface and the air flow. This is due to the cold air when to stick to the first tube hot. The air flow when it passes over the first tube gains heat, and thus the temperature difference between the second tube and the air flow is lower. Consequently, the heat transfer coefficient is smaller, as well as for the third tube. As for the reason the heat transfer coefficient of the surfaces is small at the start and then begins to increase, this is due to the hot layer being continuous between the tubes.

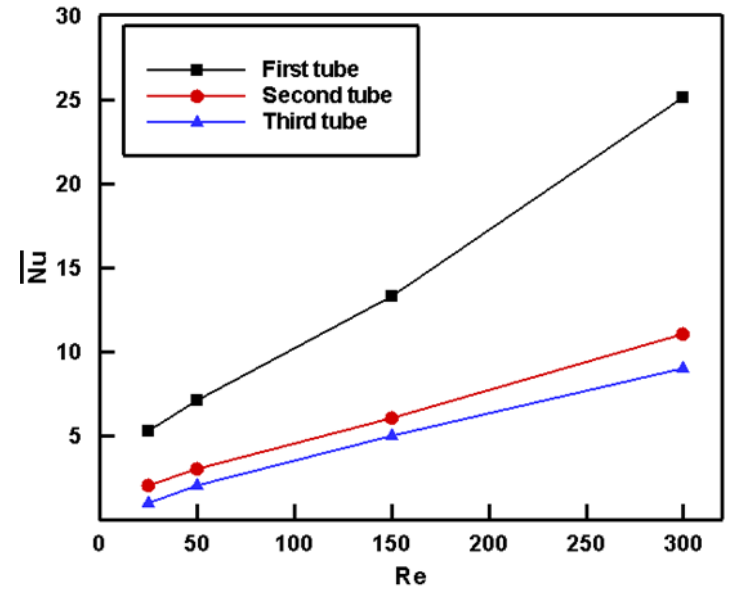

(a) $S_{L} / D_{s}=2.0$

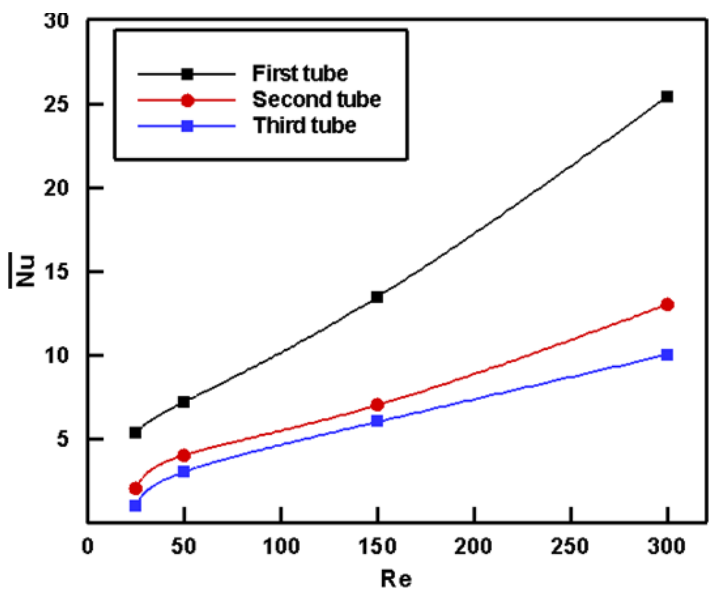

(b) $\mathrm{S}_{\mathrm{L}} / \mathrm{D}_{\mathrm{s}}=3.0$

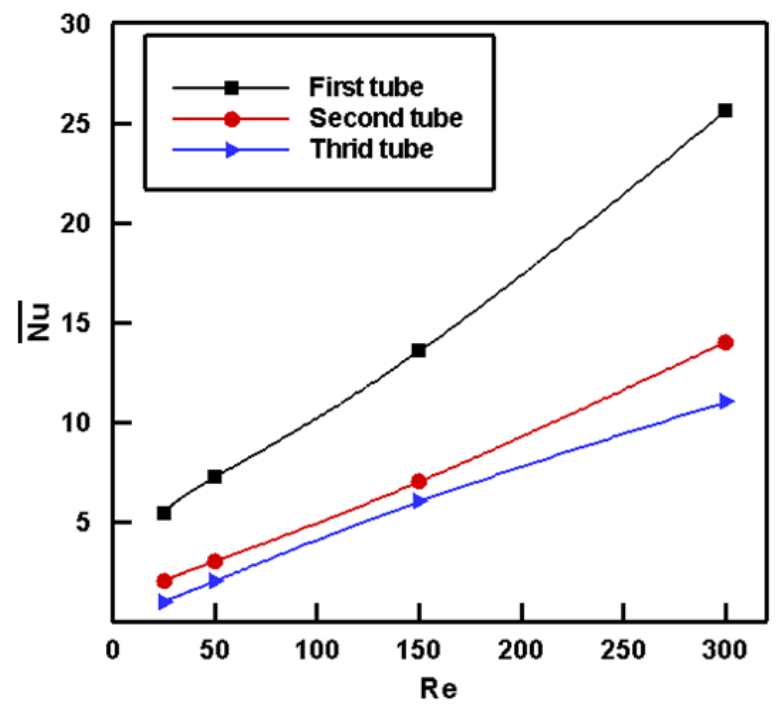

(c) $\mathrm{S}_{\mathrm{L}} / \mathrm{D}_{\mathrm{s}}=4.0$

Figure 6. Effect of Reynolds number on average Nusselt number at $\operatorname{Pr}=0.7$. 


\section{CONCLUSION}

A finite volume method with co-located variable storage in body-fitted coordinates is used to predict the heat transfer and fluid flow over three flat in-line tubes, as well as over the tube surface due to side heat transfer air flow. The numerical results for the temperature distributions, the streamlining of the air flow and the average Nusselt number were studied. The summarized results are as follows:

i) The isothermal floods decrease with an increase in Reynolds number.

ii) The flow recirculation region increases with an increase in Reynolds number.

iii) The average Nusselt number of the air flow increases with an increase in Reynolds number.

iv) Finally, the maximum Nusselt number value occurred at the first tube in comparison with the other tubes.

\section{ACKNOWLEDGEMENTS}

The authors would like to thank the Faculty of Mechanical Engineering in Universiti Malaysia Pahang (UMP) and Universiti Malaysia Pahang for their financial support under RDU110332.

\section{REFERNCES}

Achaichia, A., \& Cowell, T. A. (1988). Heat transfer and pressure drop characteristics of flat tube and louvered plate fin surfaces. Experimental Thermal and Fluid Science, 1, 147-157.

Bahaidarah, H. M. S., Ijaz, M., \& Anand, N. K. (2006). Numerical study of fluid flow and heat transfer over a series of in-line noncircular tubes confined in a parallelplate channel. Numerical Heat Transfer: Part B, 50, 97-119.

Beale, S. B., \& Spalding, D. B. (1999). A numerical study of unsteady fluid flow in inline and staggered tube banks. Journal of Fluids and Structures, 13, 723-754.

Bejan, A. (2004). Convection heat transfer. New York, John Wiley and Sons.

Benarji, N., Balaji, C., \& Venkateshan, S. P. (2008). Unsteady fluid flow and heat transfer over a bank of flat tubes. Heat and Mass Transfer, 44, 445-461.

Chen, Y., Fiebig, M., \& Mitra, N. K. (1998a). Conjugate heat transfer of a finned oval tube part B: heat transfer behaviors. Numerical Heat Transfer: Part A, 33, 387401.

Chen, Y., Fiebig, M., \& Mitra, N. K. (1998b). Conjugate heat transfer of a finned oval tube part A: flow patterns. Numerical Heat Transfer: Part A, 33, 371-385.

Fowler, A. J., \& Bejan, A. (1994). Forced convection in banks of inclined cylinders at low Reynolds numbers. International Journal of Heat and Fluid Flow, 15, 9099.

Jayavel S., \& Tiwari S. (2009). Numerical study of heat transfer and pressure drop for flow past inline and staggered tube bundles. International Journal of Numerical Methods for Heat and Fluid Flow, 19, 931-949.

Kundu, D. (1989). Computational and experimental studies of flow field and heat transfer from a row of in-line cylinders centered between two parallel plates. $\mathrm{PhD}$ Thesis, University of Texas at Arlington, USA.

Kupprn, T. (2000). Heat exchanger design handbook. New York: Madison Avenue. 
Mandhani, V. K., Chhabra, R. P., \& Eswaran, V. (2002). Forced convection heat transfer in tube banks in cross flow. Chemical Engineering Science, 57, 379391.

Marchi, C. H., \& Hobmeir, M. A. (2007). Numerical solution of staggered circular tubes in two-dimensional laminar forced convection. Journal of the Brazilian Society of Mechanical Sciences and Engineering, 29, 42-48.

Matos, R. S., Vargas, J. V. C., Laursen, T. A., \& Bejan, A. (2004). Optimally staggered finned circular and elliptic tubes in forced convection. International Journal of Heat and Mass Transfer, 47,1347-1359.

Patankar, S. V. (1980). Numerical heat transfer and fluid flow. Washington DC: Hemisphere.

Rahmani, R., Mirzaee, I., \& Shirvani, H. (2005). Computation of a laminar flow and heat transfer of air for staggered tube arrays in cross-flow. Iranian Journal of Mechanical Engineering, 6, 19-33.

Rosdzimin, A. R. M., Zuhairi, S. M., \& Azwadi, C. S. N. (2010). Simulation of mixed convective heat transfer using lattice boltzmann method. International Journal of Automotive and Mechanical Engineering, 2, 130-143.

Sumner, D. (2010). Two circular cylinders in cross-flow: a review. Journal of Fluids and Structures, 26, 849-899.

Suryanarayana, K. V., Srinivasa Rao, G., Reddy Prasad, D. M., Sharma, K. V., \& Sarma, P. K. (2011). Experimental Analysis of Heat and Mass Transfer In a Packed Bed. Journal of Mechanical Engineering and Sciences, 1, 124-132.

Thompson, J. R., Warsi, Z. U. A., \& Martin, C. W. (1997). Numerical grid generation, foundations and applications. New York: North-Holland.

Vijaya Lakshmi, B., Subrahmanyam, T., Dharma Rao, V., \& Sharma, K. V. (2011). Turbulent film condensation of pure vapors flowing normal to a horizontal condenser tube - constant heat flux at the tube wall. International Journal of Automotive and Mechanical Engineering, 4, 455-470.

Wang, Y. Q., Penner, L. A., \& Ormiston, S. J. (2000). Analysis of laminar forced convection of air for crossflow in banks of staggered tubes. Numerical Heat Transfer: Part A, 38, 319-345.

Webb, R. L. (1993). Principles of enhanced heat transfer. New York: John Wiley.

Wilson, A. S., \& Bassiouny, M. K. (2000). Modeling of heat transfer for flow across tube banks. Chemical Engineering and Processing, 39, 1-14.

Zukauskas, A. (1972). Heat transfer from tubes in crossflow. Advances in Heat Transfer, 8, 93-115. 